\title{
Precursors of Body Dissatisfaction and its Implication for Psychological Well-Being in Young Adults*
}

\section{Precursores de la insatisfacción corporal y su implicación en el bienestar psicológico en adultos jóvenes}

\author{
JaVier Molina-García ${ }^{a}$ \\ Universidad de Valencia, España \\ ORCID: http://orcid.org/0000-0001-6713-5936 \\ Isabel Castillo \\ Universidad de Valencia, España \\ ORCID: http://orcid.org/0000-0001-6821-4038 \\ Ana Queralt \\ Universidad de Valencia, España \\ ORCID: http://orcid.org/0000-0003-4933-0003 \\ Octavio Alvarez \\ Universidad de Valencia, España \\ ORCID: http://orcid.org/0000-0002-6388-8030
}

\footnotetext{
a Correspondence author. Email: javier.molina@uv.es
}

How to cite: Molina-García, J., Castillo, I., Queralt, A., \& Alverez, O. (2019). Precursors of body dissatisfaction and its implication for psychological well-being in young adults. Universitas Psychologica, 18(2), 1-11. https://doi.org/10.11144/Javeriana.upsy 18-2.pbdi

\begin{abstract}
The authors examined leisure-time physical activity (LTPA), body mass index (BMI), and perceived physical ability as body dissatisfaction antecedents, and analyzed their relationship to well-being. The sample comprised 501 university students. Data were collected using a selfadministered survey. Path analysis revealed that LTPA positively predicted perceived physical ability. BMI and perceived physical ability predicted body dissatisfaction (positively and negatively, respectively). Body dissatisfaction negatively predicted subjective vitality, whereas perceived physical ability positively predicted subjective vitality. These results support the inclusion of LTPA in intervention programs that seek to promote more satisfactory physical perceptions and psychological wellbeing.

Keywords

body image; exercise; body weight; young adult; subjective vitality.
\end{abstract}

\section{RESUMEN}

Este estudio analizó la actividad física de tiempo libre (AFTL), el índice de masa corporal (IMC) y la habilidad física percibida como antecedentes de la insatisfacción corporal, así como su relación con el bienestar. La muestra estuvo compuesta por 501 estudiantes universitarios. La recogida de información se produjo a través de un cuestionario. El análisis de vías causales mostró que la AFTL era un predictor positivo de la habilidad física percibida. La insatisfacción corporal fue predicha positivamente por el IMC y negativamente por la habilidad física. La insatisfacción corporal y la habilidad física predijeron negativamente y positivamente la vitalidad subjetiva, respectivamente. Los resultados apoyan la inclusión 
de la AFTL en programas de intervención que pretendan promover un mayor bienestar psicológico.

Palabras clave

imagen corporal; ejercicio; peso corporal; adulto joven; vitalidad subjetiva.

Body dissatisfaction has been identified as a risk factor in the development of eating disorders and related psychopathologies among youth (Franco, Mancilla, Vázquez, Álvarez, \& López, 2011; Sepulveda, Carrobles, \& Gandarillas, 2010; Sidor, Baba, Marton-Vasarhelyi, \& Chereches, 2015). Hence, it is crucial to analyze what factors contribute to the development of body dissatisfaction and body image problems (Esnaola, Rodríguez, \& Goñi, 2010; Karazsia, Murnen, \& Tylka, 2017). Body dissatisfaction has emerged as a mediator of the relationship between body composition, usually represented through body mass index (BMI), the ratio of weight to height $\left(\mathrm{kg} / \mathrm{m}^{2}\right)$ used to determine weight status (Centers for Disease Control and Prevention, 2015), and mental health outcomes, such as depressive mood and self-esteem (Mond, Van den Berg, Boutelle, Hannan, \& NeumarkSztainer, 2011). Most studies that examine body dissatisfaction and its relation to well and ill-being have focused on adolescent female populations (Ferreiro, Seoane, \& Senra, 2014; Karr, Davidson, Bryant, Balague, \& Bohnert, 2013). As a consequence, less is known regarding the role of body dissatisfaction in the relationship between BMI and psychological well-being among the general population of young adults, although some studies in university populations have indicated that body dissatisfaction is associated with lower well-being (Green et al., 2009).

Furthermore, previous research in young people and university students suggests that a higher BMI is associated with greater body dissatisfaction (Provencher et al., 2009; Téllez Suárez et al., 2014). In this regard, gender differences have been intensely reported in the literature, with female youth indicating more body dissatisfaction than males (Lawler \& Nixon, 2011). These differences, which are clearly observed in adolescent populations, seem to diminish in adult populations with increasing age (Esnaola et al., 2010; Téllez Suárez et al., 2014). In general, research has focused on the role of body dissatisfaction in the incidence of eating disorders (Ferreiro et al., 2014; Sepulveda et al., 2010), and few studies have examined the antecedents of body dissatisfaction, especially in healthy young adults.

Participation in regular physical activity, especially leisure-time physical activity (LTPA), is one factor that has a positive impact on body satisfaction and psychological well-being (De la Cruz-Sánchez, Moreno-Contreras, Pino-Ortega, \& Martínez-Santos, 2011; McCabe, Roberts, \& Morris, 1991; Molina-García, Castillo, \& Queralt, 2011; Olmedilla-Zafra \& Ortega-Toro, 2009). It is adequate to assess the overall amount of LTPA when relations between physical activity and psychological constructs are expected to be established (Molina-García et al., 2011). In this way, metabolic equivalent (MET) expenditure is a common measure of physical activity level (Ainsworth et al., 2018). Considering each one of the dimensions of physical activity (MolinaGarcía et al., 2011), usually referred to by the acronym FITT (frequency, intensity, time, and type of activity) is necessary to estimate MET energy expenditure. According to the literature, the relationship between LTPA and body satisfaction and psychological well-being can differ depending on gender, age, and the type of physical activity. In general, it seems that regardless of the variables above, the practice of taking regular physical activity is associated with higher body satisfaction and it is a way of preventing eating disorders (Furnham, Titman, \& Sleeman, 1994). Moreover, participation and success in sport promote a better perception of the physical ability which can lead to a positive body image and sense of identity (Castillo \& Molina-García, 2009; McCabe et al., 1991).

Current evidence indicates that there is a complex relationship between the different factors that can influence body dissatisfaction among those who do participate in sport (Karr et al., 2013). A study in high school females, aged 14 to 19 years of age, who participated in sport 
confirmed that both BMI and perceived ability significantly influenced body dissatisfaction (Karr et al., 2013). It would be interesting to evaluate these relationships in young adults, especially knowing that an acute decline in LTPA levels usually characterizes the transition from high school to adult life, in both gender groups, as well as by an increase in body weight (MolinaGarcía, Castillo, \& Pablos, 2009; Molina-García, Queralt, Castillo, \& Sallis, 2015; Provencher et al., 2009).

The physical self-concept is a sub-domain of the global self-concept and refers to how individuals evaluate their physical abilities (Marsh, Richards, Johnson, \& Roche, 1994). When girls perceive themselves as physically capable, for example, regarding their physical fitness, they view their bodies as instrumental or functional versus appearance-based (Marsh et al., 1994). Such a functional view of the physical self has been related to higher levels of body satisfaction in a sample of female college students participating in a study which tried to identify risk factors associated with body dissatisfaction (Cook-Cottone \& Phelps, 2003). At the general population level, it has been argued that improvements in perceived physical abilities, usually achieved through physical activity and sport experiences, could reduce the body dissatisfaction of participants through programs intended to reduce the focus on their physical appearance (Martin \& Lichtenberger, 2002).

Within the general population, considerable research has shown that regular participation in physical activity is associated with improvements in a wide range of psychological well-being (Lapa, 2015; Stathi, Fox, \& McKenna, 2002). Wellbeing is a dynamic concept that can be defined as the way people feel about themselves and is associated with the quality of life. Subjective vitality has been defined as a positive sense of aliveness and energy and is extensively used as an indicator of well-being. This definition of subjective vitality is aligning with the WHO's definition of psychological well-being as 'a state of well-being in which every individual realizes his or her potential, can cope with the normal stress of life and can work productively and effectively' (World Health Organization, 2003). The positive psychology paradigm recognizes that positive well-being experiences, such as subjective vitality are likely to covary with both physical and psychological health factors (Ryan $\&$ Frederick, 1997). For example, the perceived meaning behind the body image dissatisfaction will interfere with one's feeling of energy; nevertheless, the perceived physical abilities will determine the strength of vitality experienced. It is important to recognize that the relationship between physical activity and psychological well-being is complex. Exercise environment, psychological characteristics and skill levels of the participants can vary. Despite this, there is a consensus that regular participation in physical activity is associated with enhanced vitality and a sense of feeling better (Netz, Wu, Becker, \& Tenenbaum, 2005).

There is a lack of studies, mainly in healthy young adults, aimed at understanding the complex relationships among the antecedents of body image dissatisfaction and their consequences on psychological well-being (Wilson, Latner, \& Hayashi, 2013). Therefore, based upon empirical findings, the present study aims to examine physical activity, BMI, and perceived physical ability as antecedents of body dissatisfaction, as well as their relationship with subjective vitality among both male and female university students. It was hypothesized that physical activity levels would be predictive of lower BMI and in contrast, it was expected physical activity levels to be positively related with better perceptions of physical ability (see Figure 1). In turn, BMI was predicted to be positively associated with body dissatisfaction, whereas perceived physical ability would be predictive of lower body dissatisfaction. Finally, the authors hypothesized that body dissatisfaction would be negatively related to subjective vitality in this university student sample. 
Figure 1

Hypothesized structural model of the antecedents of body dissatisfaction and its association with psychological well-being

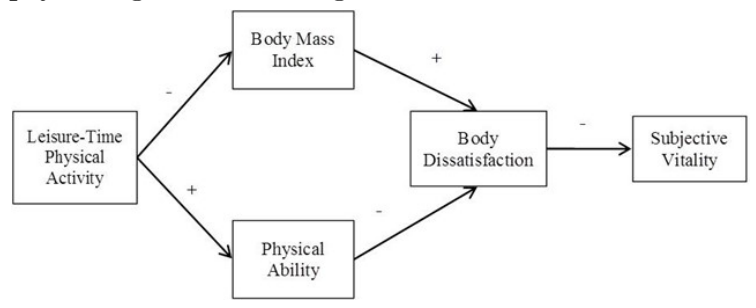

\section{Method}

Participants and Procedure

A cross-sectional study was designed. The sample comprised 501 healthy university students (59.9\% women), between 18 and 34 years old ( $M$ $=21.64, \mathrm{SD}=3.12$ ), recruited via convenience sampling. Only $11.6 \%$ of participants were classified as obese/overweight. The sample was representative of the students registered in the University of Valencia and Catholic University of Valencia, Spain. The estimation error of the sample was $\pm 5 \%$, with a confidence level of $95.5 \%$. A variety of recruitment methods were used, including mailing and phoning faculty of the universities. Participants completed a 20minute self-administered paper survey during class periods. Data were collected April and May of 2009. The authors obtained institutional approval from participating institutions for the study protocol, and written informed consent was obtained from all participants before they enrolled in the study. The voluntary nature of their participation and the confidential management of their information were explained during the elaboration of the study. The study design was conducted respecting the ethical standards for research with human participants.

\section{Measurements}

\section{Physical activity}

LTPA domain was assessed using the Spanish version of the GPAQ survey (Global Physical Activity Questionnaire; Bull, Maslin, \& Armstrong, 2009). This questionnaire, developed by $\mathrm{WHO}$, allows asessing moderate to vigorous-intensity physical activities performed during leisure time. GPAQ survey was shown as a suitable and acceptable instrument for measuring physical activity in a nine-country reliability and validity study among the adult population (Bull et al., 2009). Reliability coefficients were of moderate to substantial strength (Spearman's rho: 0.67-0.81; Kappa: 0.67-0.73) (Bull et al., 2009). The GPAQ survey has been satisfactorily used among Spanish university students in previous research (e.g., Molina-García et al., 2015). MET values, which are commonly used to state the intensity of physical activities, were used to calculate the total LTPA. One MET is the energy expenditure of sitting quietly and is approximately equivalent to $3.5 \mathrm{ml}$ of oxygen per kilogram of body weight per minute (Ainsworth et al., 2018). In this regard, 4 METs were assigned to the time spent doing moderate activities (e.g., brisk walking), and 8 METs to the time spent doing vigorous activities (e.g., running). Finally, a weekly estimation of total energy expenditure $(\mathrm{MET} \cdot \mathrm{minutes} /$ week) was obtained.

\section{Perceived physical ability}

Participants' beliefs about their physical ability were determined using the Perceived Physical Ability subscale of the Physical SelfEfficacy scale (Ryckman, Robbins, Thornton, \& Cantrell, 1982). This subscale showed adequate psychometric properties as well as a unidimensional structure (Ryckman et al., 1982). The 10 items were rated (e.g., "I have excellent reflexes") on a Likert scale ranging from 1 (strongly disagree) to 6 (strongly agree). The internal consistency (Cronbach's alpha) in the sample was 0.80 . 
BMI

Height and weight were measured using standardized protocols, and then BMI $\left(\mathrm{kg} / \mathrm{m}^{2}\right)$ was calculated. In order not to increase the possible measurement errors, it was decided to use the BMI as a continuous variable in statistical analyses.

\section{Body dissatisfaction}

The 9-item Body Dissatisfaction subscale of the revised Eating Disorders Inventory (EDI-2) was used (Garner, 1991). This scale has been validated in the Spanish population (Garner, 1998), obtaining an acceptable internal consistency. An example item is: "I am satisfied with my figure". The items were rated on a 6 point Likert scale from 1 (strongly disagree) to 6 (strongly agree). The internal consistency of this scale in this study was 0.88 .

\section{Subjective vitality}

The Spanish version (Castillo, Tomás, \& Balaguer, 2017) of the 6-item Subjective Vitality Scale (Ryan \& Frederick, 1997) was used to evaluate psychological well-being (e.g., "I feel energized"). According to Castillo et al. (2017), confirmatory factor analysis supported a unidimensional factor structure for the Spanish version of the Subjective Vitality Scale. Reliability analysis indicated a durable internal consistency ( $\alpha$ ranged from 0.82 to 0.89) (Castillo et al., 2017). Responses were rated on a 7-point scale using anchors of 1 (not at all true) and 7 (very true). The internal consistency for this scale in this study was 0.87 .

\section{Statistical Analysis}

The hypothesized model (see Figure 1) was tested with path analysis, using the maximum likelihood method included in the LISREL software, version 8.80 (Jöreskog \& Sörbom,
2006). Previously, indices estimating normality of observed data were examined. The skewness and kurtosis of all the variables were well below the most commonly used critical values for univariate normality ( \pm 3 and \pm 10 ; Kline, 2005), revealing that the distribution of all the items was fairly normal. Mardia's coefficient (0.43) supported the multivariate normality of the data. Correlations between the variables were below 0.85 , avoiding multicollinearity problems. The hypothesized model is recursive with one-way causal influences. Finally, the error term of each endogenous variable is not related to other variables, avoiding the independence of errors.

Regarding the sample size, the study follows the recommendation to include between 10 and 20 cases per parameter and more than 200 participants (Kline, 2005). Mean scores were used as targeted variable indicators. To determine the fit of the model, it was considered different indices of fit $(\mathrm{Hu} \&$ Bentler, 1995), including the chi-square $\left(\chi^{2}\right)$ test, non-normative fit index (NNFI), comparative fit index (CFI), root mean square error of approximation (RMSEA), and standardized root mean square residual (SRMR). CFI and NNFI values higher than 0.90 indicate an acceptable fit; for RMSEA and SRMR, values equal to or lower than 0.08 are considered optimal. Most other analyses, including descriptive statistics, $\mathrm{t}$ tests and correlations, were performed using the Statistical Package for the Social Sciences (SPSS) version 20.0.

\section{Results}

The descriptive statistics and gender differences for all the study variables are presented in Table 1. Independent-sample t-tests showed that males scored significantly higher than females for LTPA, BMI, perceived physical ability, and subjective vitality. Females scored significantly higher than males on body dissatisfaction. Taking these results into account, subsequent analyses were performed separately by gender. 
Table 1

Descriptives and gender differences among the study variables

\begin{tabular}{|c|c|c|c|c|c|c|c|}
\hline \multirow{2}{*}{ Variables } & \multirow{2}{*}{ Min } & \multirow{2}{*}{ Max } & \multicolumn{2}{|c|}{ Males } & \multicolumn{2}{|c|}{ Females } & \multirow{2}{*}{$t$} \\
\hline & & & $M$ & $S D$ & $M$ & $S D$ & \\
\hline $\begin{array}{l}\text { Leisure-Time Physical } \\
\text { Activity (MET } \text { min }_{\text {week }} \text { ) }\end{array}$ & 0 & $\begin{array}{r}1344 \\
0\end{array}$ & 3481.69 & 2651.27 & 1243.53 & 1760.37 & $10.52^{* *}$ \\
\hline Physical Ability & 2 & 6 & 4.64 & 0.66 & 3.87 & 0.73 & $11.87^{* *}$ \\
\hline Body Mass Index $\left(\mathrm{kg} / \mathrm{m}^{2}\right)$ & 16.53 & 41.97 & 23.31 & 2.51 & 21.36 & 2.75 & $8.02 * *$ \\
\hline Body Dissatisfaction & 1 & 5.89 & 2.41 & 0.8 & 3.06 & 1.03 & $-7.95 * *$ \\
\hline Subjective Vitality & 2.17 & 7 & 5.32 & 0.97 & 4.91 & 1.05 & $4.52^{* *}$ \\
\hline
\end{tabular}

Table 2 shows the bivariate Pearson correlations between the different variables. LTPA was significantly positively associated with physical ability and with subjective vitality in both males and females. Furthermore, in both genders, physical activity was not significantly related to BMI or body dissatisfaction. Body dissatisfaction and physical ability were significantly negatively associated with both genders. Furthermore, body dissatisfaction and BMI were significantly positively associated, whereas body dissatisfaction and subjective vitality were significantly negatively related in both genders. Finally, subjective vitality was positively and significantly associated with physical ability in both genders, whereas subjective vitality was negatively and significantly related to BMI in females but not in males.

\section{Table 2}

Bivariate Pearson correlations between the study variables

\begin{tabular}{lccccc}
\hline \multicolumn{1}{c}{ Variables } & $\mathbf{1}$ & $\mathbf{2}$ & $\mathbf{3}$ & $\mathbf{4}$ & $\mathbf{5}$ \\
\hline 1. Leisure-time Physical Activity & - & $0.38^{* *}$ & 0.01 & -0.02 & $0.19^{* *}$ \\
2. Physical Ability & $0.16^{*}$ & - & 0.05 & $-0.21^{* *}$ & $0.30^{* *}$ \\
3. Body Mass Index & 0.01 & 0.01 & - & $0.47^{* *}$ & $-0.11^{*}$ \\
4. Body dissatisfaction & -0.03 & $-0.41^{* *}$ & $0.43^{* *}$ & - & $-0.16^{* *}$ \\
5. Subjective Vitality & $0.15^{*}$ & $0.41^{* *}$ & 0.09 & $-0.21^{* *}$ & - \\
\hline
\end{tabular}

NoteMale correlations are located below the diagonal and female correlations are located above the diagonal. $* p<0.05 ; * p<0.01$

Initially, the hypothesized model fitted poorly to the data for both genders [males: $\chi^{2}(5)=$ $31.25, p<0.01 ; \mathrm{CFI}=0.85 ; \mathrm{NNFI}=0.49$; RMSEA $=0.16(90 \% \mathrm{CI}=0.11-0.22)$; SRMR $=0.10$; and females: $\chi^{2}(5)=30.49, p<0.01$; $\mathrm{CFI}=0.838 ; \mathrm{NNFI}=0.67$; $\mathrm{RMSEA}=0.131$ $(90 \% \mathrm{CI}=0.09-0.17) ;$ SRMR $=0.084]$. The Modification Indices suggested adding a path from perceived physical ability and subjective vitality and following this the re-estimated model adequately fitted to the data from both males and females [males: $\chi^{2}(4)=8.12, p>0.01$; $\mathrm{CFI}=0.98 ; \mathrm{NNFI}=0.92 ; \mathrm{RMSEA}=0.066$ $(90 \% \mathrm{CI}=0-0.15) ;$ SRMR $=0.033$; and females: $\chi^{2}(4)=8.17, p>0.01 ; \mathrm{CFI}=$ $0.98 ; \mathrm{NNFI}=0.95 ;$ RMSEA $=0.059(90 \%$ $\mathrm{CI}=0-0.096) ;$ SRMR $=0.034]$. The data obtained showed that physical activity levels positively predicted perceived physical ability in both genders (Figure 2). Body dissatisfaction was positively predicted by BMI and negatively predicted by perceived physical ability in both genders and perceived physical ability positively predicted subjective vitality in both genders. Lastly, body dissatisfaction acted as a negative predictor of subjective vitality in males and in females. The proposed model accounted for 36\% of the variance of body dissatisfaction, $17 \%$ of the variance of subjective vitality in males; and $28 \%$ of the variance of body dissatisfaction and $10 \%$ of the variance of subjective vitality in females.

Figure 2

Revised-model of the antecedents of body dissatisfaction and its association with psychological well-being

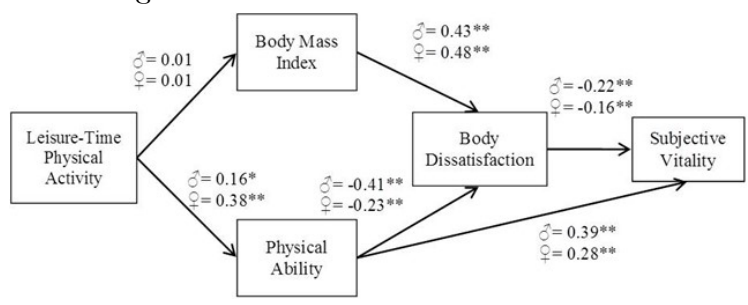

Note. All the coefficients are standardized. $*_{p}<0.05 ; * *_{p}<0.01$; \#: men; \#: women.

The standardized indirect effects indicated that in females' physical activity levels were negatively linked to body dissatisfaction $(\beta=$ $-0.08, p<0.05)$ and positively linked to subjective vitality $(\beta=0.11, p<0.05)$ through perceived physical ability. 


\section{Discussion}

The main objective of this study was to analyze the relationships between physical activity, body weight status, and perceived physical ability as antecedents of body dissatisfaction by testing them in a structural equation model, and then to assess their impact on psychological well-being. In this model, which was tested with young adults, similar associations were found between the study variables in both genders.

LTPA emerged as an antecedent that can influence body satisfaction, and consequently, psychological well-being, among young people. LTPA can improve perceptions of the physical ability which, on a practical level, suggests that levels of physical activity sufficient to allow positive experiences and the development of better perceptions of physical competence should be encouraged (Castillo \& Molina-García, 2009; Castillo, Molina-García, \& Álvarez, 2010). Future studies should specifically analyze the role of the context, such as the motivational climate and autonomous support where the physical activity occurs (Harwood, Keegan, Smith, \& Raine, 2015), and the relationships between LTPA, the perception of physical ability, and body satisfaction.

The fact that the influence of perceived physical ability on body dissatisfaction was similar in men and women contrasts with the literature about adolescents (McCabe et al., 1991). From mid-adolescence, the athletic ability seems to be the main influence on body satisfaction among boys; however, girls are more specifically influenced by factors other than physical ability, such as social attitudes (Esnaola et al., 2010; Karr et al., 2013). It seems that, in young adulthood, both boys and girls can benefit from regular and satisfactory physical activity, which helps them to form a positive body image perception through positive evaluations of their physical ability. In other words, when young people perceive themselves as more athletically competent, they have more favorable attitudes towards their body image and they feel that they have more energy and vitality.
On the other hand, it is well known that regular LTPA among young adults is often associated with lower, and therefore healthier, body weights (Molina-Garcia et al., 2009; Molina-García et al., 2015; Provencher et al., 2009). In contrast, in the present study, the authors could not discern a significant relationship between LTPA and BMI, either men or women. Future longitudinal studies should, therefore, evaluate how potential weight gain during the 20s (Lewis et al., 2000), caused by decreases in LTPA, affects physical perceptions and psychological well-being.

Consistent with the present findings, another recent study conducted in a sample of 414 undergraduate students with a mean age of 22 years, showed that body image dissatisfaction mediated the association between BMI and health-related quality of life in men and women (Wilson et al., 2013). In the present study, university students with higher BMI were less satisfied with their body image compared to those with less body weight. These results help to clarify the relationships between body weight, body image, and mental health in young adults.

As evidence in the literature regarding adolescents has already shown (Lawler \& Nixon, 2011), this study noted gender differences in the level of body dissatisfaction, with females showing greater dissatisfaction. In contrast, other studies suggest a reduction in, or the absence of, gender differences in body satisfaction among adult populations (Esnaola et al., 2010; Téllez Suárez et al., 2014). Perhaps these differences could be explained by differences in physical activity level between the genders, in favor of men. Lower levels of LTPA among women have been systematically reported in different studies looking at different age groups (RomanViñas et al., 2016). The present results justify the consideration of public health intervention programs that seek to improve the LTPA levels of the population, especially among women, in order to avoid body dissatisfaction and promote psychological well-being.

A relevant aspect of this study is that, in the female group, LTPA indirectly predicts lower body dissatisfaction and greater vitality. These 
results, which were not found in men, empirically confirm certain gender differences with regard to the effects of regular physical activity on body dissatisfaction and psychological wellbeing. They also highlight that the relationships between body dissatisfaction antecedents are complex and can be mediated by other variables. In this respect, understanding the mechanisms of the relationships between antecedents of body dissatisfaction and well-being can be very useful for public health research and the development of effective exercise programs. This is of particular interest among women because, as previously mentioned, they tend to be less physically active and also perceive themselves to be less physically competent (Castillo \& MolinaGarcía, 2009).

A limitation of this study is its transversal nature, which only allows us to talk about associations between variables and not causeeffect situations. However, although the structural equation models do not prove causation, they do suggest causal connections, and therefore, they are relevant to the current research as statistical analysis techniques. Another limitation is that the authors did not evaluate the eating habits of the university students participating in this study. Future studies on body dissatisfaction and psychological well-being should seek to integrate eating habit assessments, as well as physical activity evaluations, into the same analysis model, because eating variables have been associated with both body image perception and mental health (Ackard, Croll, \& Kearney-Cooke, 2002). Finally, the use of a non-representative sample of university students limits the generalizability of the findings.

The present findings revealed similar associations between the model variables in both genders; BMI and perceived physical ability were significant antecedents of body dissatisfaction. These results support the inclusion of LTPA in intervention programs that seek to promote more satisfactory physical perceptions. In practice, an increase in physical activity levels would have a positive impact on improving body image satisfaction and can be considered an effective strategy for preventing the development of eating disorders and psychopathologies among young adults. In conclusion, the present findings suggest that body dissatisfaction may be a key target for psychological well-being interventions and programs.

\section{References}

Ackard, D. M., Croll, J. K., \& Kearney-Cooke, A. (2002). Dieting frequency among college females: association with disordered eating, body image, and related psychological problems. Journal of Psychosomatic Research, 52 (3), 129-136. https://doi.org/10.1016/SO 022-3999(01)00269-0

Ainsworth, B. E., Watson, K. B., Ridley, K., Pfeiffer, K. A., Herrmann, S. D., Crouter, S. E., ... \& Berrigan, D. (2018). Utility of the Youth Compendium of Physical Activities. Research Quarterly for Exercise and Sport, 89(3), 273-281. https://doi.org/10.1080/02 701367.2018.1487754

Bull, F. C., Maslin, T. S., \& Armstrong, T. (2009). Global physical activity questionnaire (GPAQ): nine country reliability and validity study. Journal of Physical Activity and Health, 6, 790-804. Retrieved from https://pdfs.semanticscholar.org/45fd/ 9a5df90a3ba5580428c3d3cc85e8c141a82 6.pdf

Castillo, I., \& Molina-García, J. (2009). Adiposity and psychological well-being: effects of physical activity on university students in Valencia, Spain. Revista Panamericana de Salud Pública, 26, 334-340. Retrieved from https://www.scielosp.org/pd f/rpsp/2009.v26n4/334-340/es

Castillo, I., Molina-García, J., \& Álvarez, O. (2010). Importance of perceived competition and motivation to the mental health of college athletes. Salud Pública de México, 52, 517-523. Retrieved from https://www.redalyc.org/pdf/106/1061 8968005.pdf

Castillo, I., Tomás, I., \& Balaguer, I. (2017). The Spanish-version of the Subjective 
Vitality Scale: Psychometric properties and evidence of validity. The Spanish Journal of Psychology, 20, e26, 1-8. https://doi.org/10. 1017/sjp.2017.22

Centers for Disease Control and Prevention. (2015). Body mass index. Retrieved from http://www.cdc.gov/healthyweight/as sessing/bmi.

Cook-Cottone, C., \& Phelps, L. (2003). Body dissatisfaction in college women: identification of risk and protective factors to guide college counseling practices. Journal of College Counseling, 6(1), 80-89. https://doi.org/10.1002/j.2161-1882 .2003.tb00229.x

De la Cruz-Sánchez, E., Moreno-Contreras, M. I., Pino-Ortega, J., \& Martínez-Santos, R. (2011). Actividad física durante el tiempo libre y su relación con algunos indicadores de salud mental en España [Leisure time physical activity and its relationships with some mental health indicators in Spain through the National Health Survey]. Salud Mental, 34(1), 45-52.

Esnaola, I., Rodríguez, A., \& Goñi, A. (2010). Body dissatisfaction and perceived sociocultural pressures: gender and age differences. Salud Mental, 33(1), 21-29.

Ferreiro, F., Seoane, G., \& Senra, C. (2014). Toward understanding the role of body dissatisfaction in the gender differences in depressive symptoms and disordered eating: A longitudinal study during adolescence. Journal of Adolescence, 37(1), 73-84. https:// doi.org/10.1016/j.adolescence.2013.10.013

Franco, P. K., Mancilla, D. J. M., Vázquez, A. R., Álvarez, R. G., \& López, A. X. (2011). El papel del perfeccionismo en la insatisfacción corporal, la influencia sociocultural del modelo de delgadez y los síntomas de trastorno del comportamiento alimentario [Perfectionism in body dissatisfaction, sociocultural influence of the thinness model and symptoms of eating disorders]. Universitas Psychologica, 10(3), 829-840. https://doi.org/10.11144/ Javeriana.upsy10-3.ppic
Furnham, A., Titman, P., \& Sleeman, E. (1994). Perception of female body shapes as a function of exercise. Journal of Social Behavior and Personality, 9, 335-352.

Garner, D. M. (1991). Eating Disorder Inventory-2. Odessa: Psychological Assessment Resources.

Garner, D. M. (1998). Inventario de Trastornos de la Conducta Alimentaria (EDI-2)-Manual. Madrid: TEA.

Green, M. A., Scott, N. A., Cross, S. E., Liao, K. Y., Hallengren, J. J., Davids, C. M., ... \& Jepson, A. J. (2009). Eating disorder behaviors and depression: a minimal relationship beyond social comparison, selfesteem, and body dissatisfaction. Journal of Clinical Psychology, 65(9), 989-999. https:// doi.org/10.1002/jclp.20586

Harwood, C. G., Keegan, R. J., Smith, J. M., \& Raine, A. S. (2015). A systematic review of the intrapersonal correlates of motivational climate perceptions in sport and physical activity. Psychology of Sport and Exercise, 18, 9-25. https://doi.org/10.1016/j.psychsport.2 014.11 .005

Hu, L., \& Bentler, P. M. (1995). Evaluating model fit. In R. H. Hoyle (Ed.), Structural equation modeling: concepts, issues and applications (pp. 76-99). Thousand Oaks, CA: Sage.

Jöreskog, K. G., \& Sörbom, D. (2006). LISREL 8.80: structural equation modeling with the SIMPLIS command language. Chicago, IL: Scientific Software International.

Karazsia, B. T., Murnen, S. K., \& Tylka, T. L. (2017). Is body dissatisfaction changing across time? A cross-temporal metaanalysis. Psychological Bulletin, 143(3), 293320. https://doi.org/10.1037/bul0000081

Karr, T. M., Davidson, D., Bryant, F. B., Balague, G., \& Bohnert, A. M. (2013). Sport type and interpersonal and intrapersonal predictors of body dissatisfaction in high school female sport participants. Body Image, 10(2), 210-219. https://doi.org/10.1 016/j.bodyim.2012.11.001

Kline, R. B. (2005). Principles and practice of structural equation modeling ( $2 \mathrm{nd}$ ed.). New York, NY: Guilford. 
Lapa, T. Y. (2015). Physical activity levels and psychological well-being: a case study of university students. Procedia-Social and Behavioral Sciences, 186, 739-743. https://d oi.org/10.1016/j.sbspro.2015.04.122

Lawler, M., \& Nixon, E. (2011). Body dissatisfaction among adolescent boys and girls: the effects of body mass, peer appearance culture and internalization of appearance ideals. Journal of Youth and Adolescence, 40 (1), 59-71. https://doi.org/1 0.1007/s10964-009-9500-2

Lewis, C. E., Jacobs, D. R. Jr., McCreath, H., Kiefe, C. I., Schreiner, P. J., Smith, D. E., \& Williams, O. D. (2000). Weight gain continues in the 1990s: 10-year trends in weight and overweight from the CARDIA study. Coronary artery risk development in young adults. American Journal of Epidemiology, 151(12), 1172-1181. https://d oi.org/10.1093/oxfordjournals.aje.a010167

Marsh, H. W., Richards, G. E., Johnson, S., \& Roche, L. (1994). Physical selfdescription questionnaire: psychometric properties and a multitrait-multimethod analysis of relations to existing instruments. Journal of Sport and Exercise Psychology, 16(3), 270-305. https://doi.org/10.1123/jse p.16.3.270

Martin, K. A., \& Lichtenberger, C. M. (2002). Fitness enhancement and changes in body image. In T. F. Cash \& T. Pruzinsky (Eds.), Body image: a handbook of theory, research, and clinical practice (pp. 414-421). New York: Guilford Press.

McCabe, A. E., Roberts, B. T., \& Morris, T. E. (1991). Athletic activity, body image, and adolescent identity. In L. Diamant (Ed.), Mind-body maturity: psychological approaches to sports, exercise, and fitness (pp. 91-103). New York: Hemisphere.

Molina-García, J., Castillo, I., \& Pablos, C. (2009). Determinants of leisure-time physical activity and future intention to practice in Spanish college students. The Spanish Journal of Psychology, 12(1), 128-137. https://doi.org/10.1017/S1138741 600001542
Molina-García, J., Castillo, I., \& Queralt, A. (2011). Leisure-time physical activity and psychological well-being in university students. Psychological Reports, 109(2), 453-460. https://doi.org/10.2466/06.10.13. PR0.109.5.453-460

Molina-García, J., Queralt, A., Castillo, I., \& Sallis, J. F. (2015). Changes in physical activity domains during the transition out of high school: psychosocial and environmental correlates. Journal of Physical Activity and Health, 12(10), 1414-1420. https://doi.org/10.1123/jpah.20 $14-0412$

Mond, J., Van den Berg, P., Boutelle, K., Hannan, P., \& Neumark-Sztainer, D. (2011). Obesity, body dissatisfaction, and emotional wellbeing in early and late adolescence: findings from the project EAT study. Journal of Adolescent Health, 48(4), 373-378. https://d oi.org/10.1016/j.jadohealth.2010.07.022

Netz, Y., Wu, M. J., Becker, B. J., \& Tenenbaum, G. (2005). Physical activity and psychological well-being in advanced age: meta-analysis of intervention studies. Psychology and Aging, 20(2), 272-284. https ://doi.org/10.1037/0882-7974.20.2.272

Olmedilla-Zafra, A., \& Ortega-Toro, E. (2009). Incidencia de la práctica de actividad física sobre la ansiedad y depresión en mujeres: perfiles de riesgo [Effect of physical activity on anxiety and depression among women: risk profiles]. Universitas Psychologica, 8(1), 105-116. Retrieved from https://revistas.javeriana.edu.co/inde x.php/revPsycho/article/view/227

Provencher, V., Polivy, J., Wintre, M. G., Pratt, M. W., Pancer, S. M., Birnie-Lefcovitch, S., \& Adams, G. R. (2009). Who gains or who loses weight? Psychosocial factors among first-year university students. Physiology $\mathbb{E}$ Behavior, 96(1), 135-141. https://doi.org/10 .1016/j.physbeh.2008.09.011

Roman-Viñas, B., Marin, J., Sánchez-López, M., Aznar, S., Leis, R., Aparicio-Ugarriza, R., ... \& Serra-Majem, L. (2016). Results from Spain's 2016 report card on physical activity for children and youth. Journal of Physical 
Activity and Health, 13(Suppl 2), S279S283. https://doi.org/10.1123/jpah.2016-03 08

Ryan, R. M., \& Frederick, C. (1997). On energy, personality, and health: subjective vitality as a dynamic reflection of well-being. Journal of Personality, 65 (1), 529-565. https://doi.or g/10.1111/j.1467-6494.1997.tb00326.x

Ryckman, R. M., Robbins, M. A., Thornton, B., \& Cantrell, P. (1982). Development and validation of a physical self-efficacy scale. Journal of Personality and Social Psychology, 42 (5), 891-914. http://doi.apa.org/journals/ psp/42/5/891.pdf

Sepulveda, A., Carrobles, J. A., \& Gandarillas, A. M. (2010). Associated factors of unhealthy eating patterns among Spanish university students by gender. The Spanish Journal of Psychology, 13(1), 364-375. https://doi.org/ 10.1017/S1138741600003929

Sidor, A., Baba, C. O., Marton-Vasarhelyi, E., \& Chereches, R. M. (2015). Gender differences in the magnitude of the associations between eating disorders symptoms and depression and anxiety symptoms. Results from a community sample of adolescents. Journal of Mental Health, 24(5), 294-298. https://doi.org/10.3 109/09638237.2015.1022250

Stathi, A., Fox, K., \& McKenna, J. (2002). Physical activity and dimensions of subjective well-being in older adults. Journal of Aging and Physical Activity, 10(1), 76-91. https://doi.org/10.1123/japa.10.1.76

Téllez Suárez, E., Castillo Biscari, N., García Quesada, S., Yagüe Lobo, I., Requena Angulo, M., Olmedilla Ishishi, Y. L., ... \& Andía Melero, V. M. (2014). Satisfacción con la propia imagen corporal en una población de estudiantes universitarios de la Comunidad de Madrid [Satisfaction with body image in a universitary population of the Comunidad de Madrid]. Nutrición Hospitalaria, 31(3), 1423-1426. https://doi. org/10.3305/nh.2015.31.3.8349

Wilson, R. E., Latner, J. D., \& Hayashi, K. (2013). More than just body weight: the role of body image in psychological and physical functioning. Body Image, 10(3), 644-647. https://doi.org/10.1016/j.bodyim. 2013.04.007

World Health Organization. (2003). Investing in mental health. Geneva: WHO.

\section{Notes}

* Research article. 